\title{
Integrasi Sistem Telerobotik dengan Simulasi Virtual Reality dan Sensor Gesture
}

\author{
Victor Sinaga S.T., Nadya Febiani S.T., Ir. Estiyanti Ekawati, MT. PhD., \\ dan Aswin Indraprastha, ST., MT., M.Eng., Ph.D. \\ Program Studi Teknik Fisika , Fakultas Teknologi Industri \\ Institut Teknologi Bandung \\ victor.sinaga021@gmail.com
}

\begin{abstract}
.
Perkembangan sistem telerobotik berkembang cukup pesat dengan berbagai fungsi dan keperluan, didukung perkembangan platform dan sumber daya yang bersifat bebas dan terbuka untuk dikembangkan (open source). Salah satu teknologi ini adalah teknologi simulasi Virtual Reality mobile yang memungkinkan keterlibatan pengguna secara intuitif dan immersive. Penelitian ini bertujuan untuk merancang dan mengimplementasikan sistem telerobotik yang intuitif dan immersive melalui teknologi simulasi Virtual Reality. Sistem telerobotik ini terdiri dari dua bagian robot. Bagian pertama adalah arm-type robot dengan tiga derajat kebebasan (3DOF) berdasarkan model MeArm yang digerakan oleh tiga motor servo analog-feedback. Bagian kedua adalah mobile-robot dengan chassis akrilik dan penggerak dua motor DC yang dapat bergerak dinamis dalam dua dimensi. Pengguna dapat memerintahkan pergerakan robot ini melalui aplikasi simulasi Virtual Reality, dan terhubung secara nirkabel melalui jaringan Wi-Fi dan internet. Sistem komando jarak jauh ini mempengaruhi akurasi pergerakan robot. Pada arm-type robot, dihasilkan akurasi komponen motor servo $1(\mathrm{\gamma})$ sebesar 80,45\%, motor servo $2(\alpha)$ sebesar 99,29\%, motor servo $3(\beta)$ sebesar 89,05\%. Adapun pada mobile-type robot didapatkan tingkat akurasi motor DC 1 sebesar 78,37\%, dan motor DC 2 sebesar $81,67 \%$.
\end{abstract}

Kata kunci: Virtual Reality, immersive, 3DOF, arm-type robot, mobile-robot, Wi-Fi.

\section{Pendahuluan}

Sistem telerobotik merupakan sistem pengendalian robot terintegrasi yang dapat dikendalikan dari jarak jauh. Sistem telerobotik sendiri merupakan salah satu bentuk implementasi sistem kontrol. Seiring dengan perkembangan teknologi, sistem kontrol dalam bidang industri digunakan untuk pengontrolan pergerakan mekanik, tekanan, temperatur, dan aliran fluida [1]. Dewasa ini, interaksi manusia dengan sistem kontrol semakin berkembang dan intuitif. Aspek ini difasilitasi melalui Human Machine Interface (HMI) [2] dan perangkat interaksi seperti Kinect atau Virtual Reality (VR). Pada tahun 2012, mulai dikembangkan gesture command menggunakan Kinect, seperti pengembangan gesture-based game menggunakan Microsoft Kinect [3]. Pada tahun 2014, mulai dikembangkan kontrol berbasis kinect-gesture untuk imitasi gerak manusia pada robot [4]. Di Indonesia, tahun 2015 telah dilakukan penelitian tentang kompensasi gangguan angin pada quadrotor melalui gesture-based interface menggunakan Kinect [5]. Kemudian pada tahun 2016, mulai dikembangkan interaksi manusia dengan sistem kontrol melalui teknologi Virtual Reality (VR) tentang model respon command pada Virtual environment atau Virtual world (dunia Virtual) [6].

Kemudian muncul pula konsep bahwa sistem kontrol memiliki kemampuan mengirim data melalui jaringan internet tanpa memerlukan interaksi fisik langsung dengan pengguna. Konsep ini disebut Internet of Things (IoT). Dengan memanfaatkan jaringan dan implementasi teknologi loT ini, dapat dirancang suatu sistem telerobotik tetap mempertahankan kualitas sistem kontrol yang dimiliki [7].

Penerapan IoT pada sistem kontrol disebut sebagai Cyber-Physical System (CPS). Konsep dasar CPS adalah suatu sistem otomasi yang memungkinkan saling terhubungnya fungsi suatu sistem di dunia fisis dengan perangkat komputasi dan komunikasi. Dengan demikian, CPS dapat didukung dengan jaringan IoT dalam keterhubungan antar jaringannya untuk dapat berfungsi. Sistem kontrol, khususnya CPS, terdiri dari mikrokontroler yang berfungsi untuk mengontrol sensor dan aktuator yang dibutuhkan untuk berinteraksi dengan sistem fisis di dunia nyata dan memproses data yang diperoleh. Salah satu karakteristik yang 
ditekankan pada CPS adalah memungkinkan pertukaran data hasil pemrosesan dari komputasi di dunia Virtual dan dunia fisis. Dapat dikatakan CPS membentuk suatu embedded system yang mampu mengirim dan menerima data dalam suatu jaringan [8] [9].

Pada penelitian ini, akan dibuat suatu sistem dengan interaksi antara pengguna dan sistem telerobotik menggunakan teknologi VR, gesture sensor dan loT. Sistem robot yang akan ditangani adalah arm-type robot dan mobile-robot. Sistem ini dibangun dengan kelengkapan komponen agar dapat memfasilitasi implementasi kontrol pada sistem robotik pada pengembangan lanjutannya. Adapun pada tahap ini, peneltian difokuskan pada integrasi sistem robot dengan teknologi VR, gesture sensor dan loT.

\section{Perancangan Sistem Telerobotik}

Sistem telerobotik pada penelitian ini dirancang agar sistem robot dapat dikomando secara nirkabel dari suatu pengendali berbasis aplikasi Virtual Reality. Bagian-bagian robot dibagi menjadi 3 bagian yaitu :

- $\quad$ Bagian mekanik robot yang akan dibagi lagi menjadi 2 bagian Arm-Type Robot dan Mobile -Type Robot

- Bagian elektrik robot

- Human Machine Interface (HMI) Robot dengan menggunakan Virtual Reality (VR)

Dengan menggunakan konsep loT/CPS, dirancang sistem telerobotik yang ditunjukkan pada Gambar 2.1.

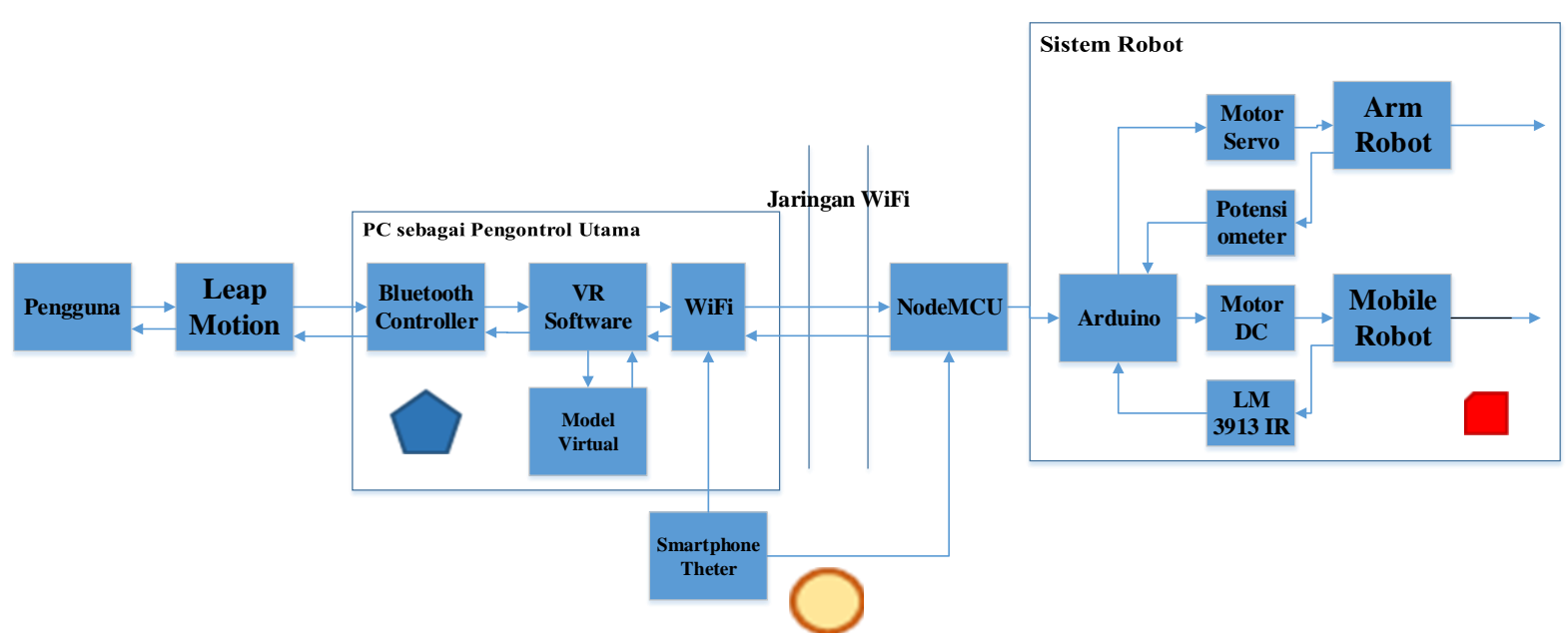

Gambar 2.1 Arsitektur Sistem Telerobotik

\subsection{Perancangan Bagian Arm-Type Robot}

Perancangan arm-type robot dilakukan dengan menggunakan Solidworks 2017. Model arm-type robot ini mengikuti model robot MeArm v3.0 yang memiliki tiga derajat kebebasan (3 DOF) dan memiliki end effector berbentuk capit [10]. Pada arm-type robot dipasang empat buah motor servo analog-feedback sebagai aktuator yang dilengkapi dengan sensor gerakannya. Masing-masing motor servo memiliki fungsi gerak dengan rincian sebagai berikut:

- $\quad$ Motor servo nomor 1 melakukan gerakan yaw (geleng), sudut yang dikontrol adalah sudut $\mathrm{y}$.

- $\quad$ Motor servo nomor 2 melakukan gerakan pitch (angguk) pada lengan kanan arm-type robot, sudut yang dikontrol adalah sudut $\alpha$. 
- $\quad$ Motor servo nomor 3 melakukan gerakan pitch (angguk) pada lengan kiri arm-type robot, sudut yang dikontrol adalah sudut $\beta$.

- $\quad$ Motor servo nomor 4 pada end effector khusus mengendalikan capit.

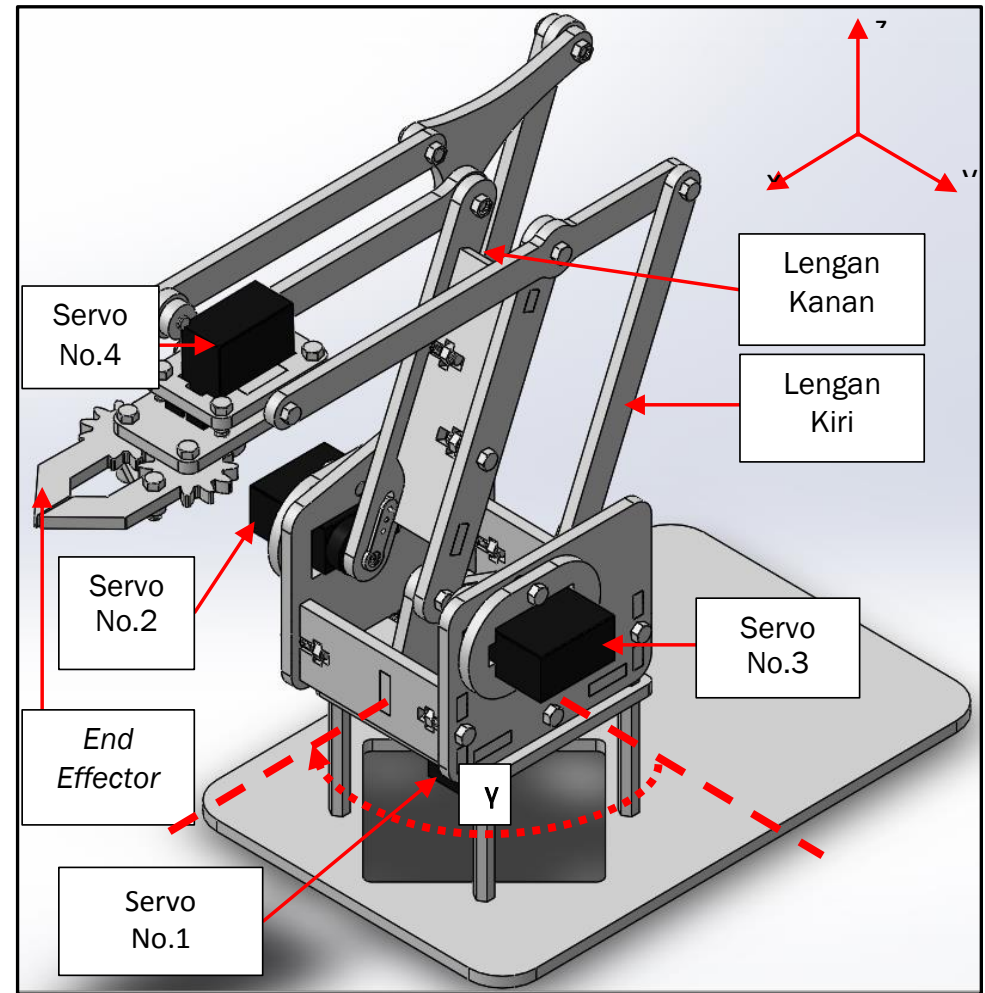

Gambar 2.2 Arm-Type Robot dan Sudut y yang Digerakkan Motor Servo 1

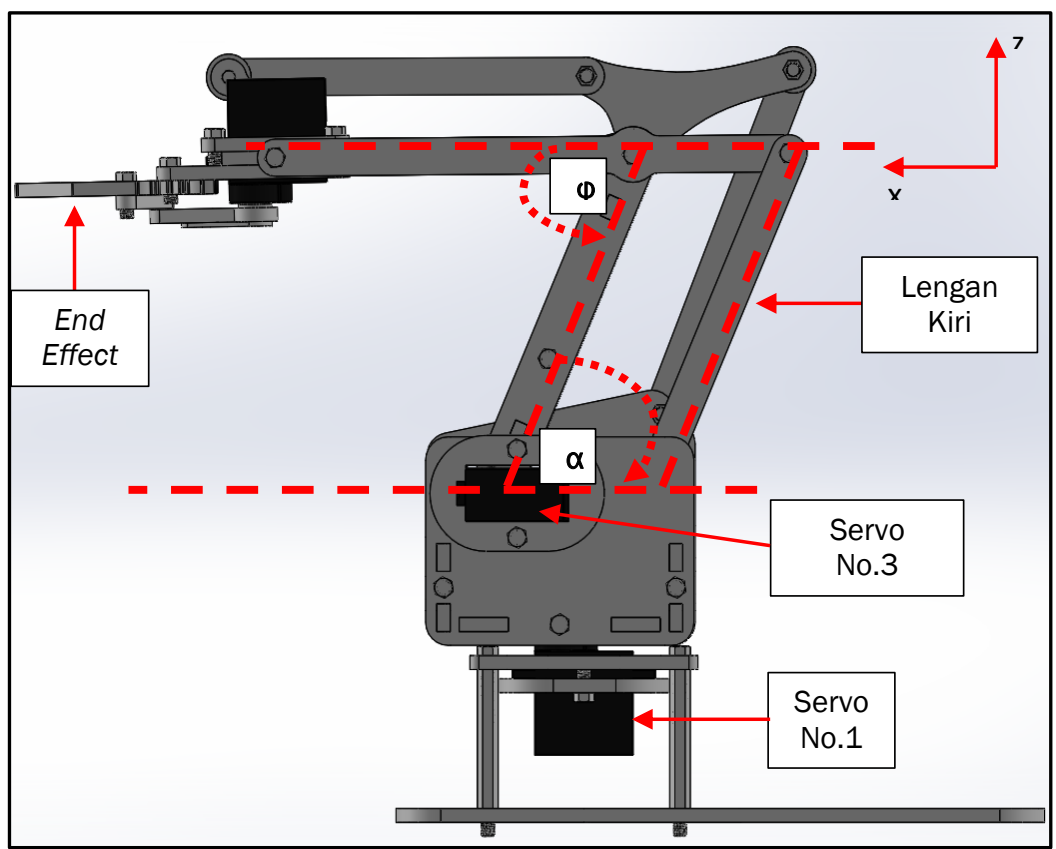

Gambar 2.3 Arm-Type Robot dan Sudut $\alpha$ yang Digerakkan Motor Servo Nomor 2 


\subsection{Perancangan Bagian Mobile-Type Robot}

Perancangan mobile-robot lebih mudah karena hanya berupa pemasangan motor DC pada chassis akrilik. Chassis akrilik dirancang agar dapat menjadi tempat memasang dua motor DC, bagian dock dari arm-type robot, dan menaruh dua sensor LM319 IR untuk mendeteksi kecepatan putar motor DC.

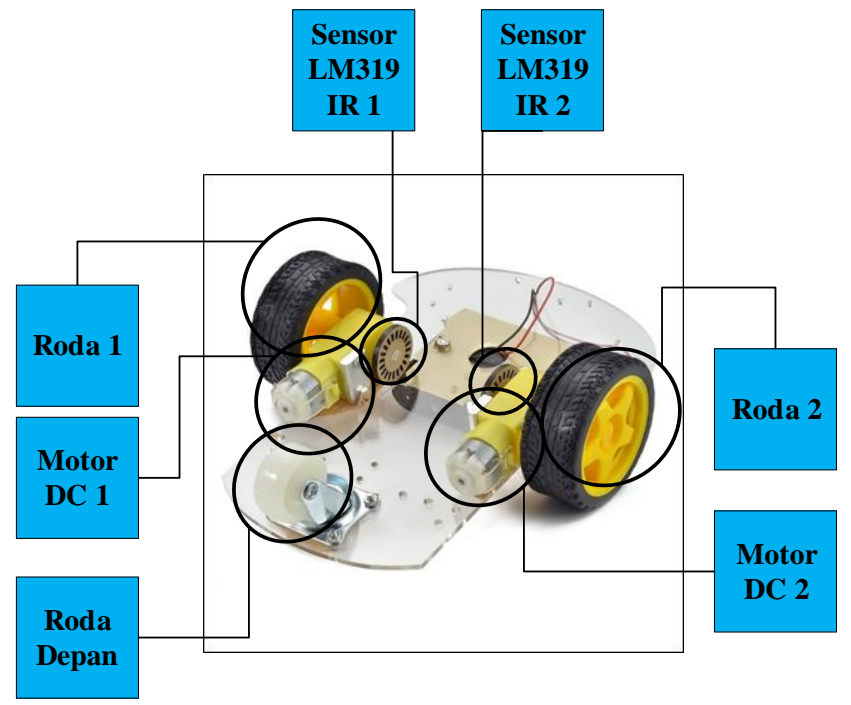

Gambar 2.4 Rangkaian Mobile type Robot

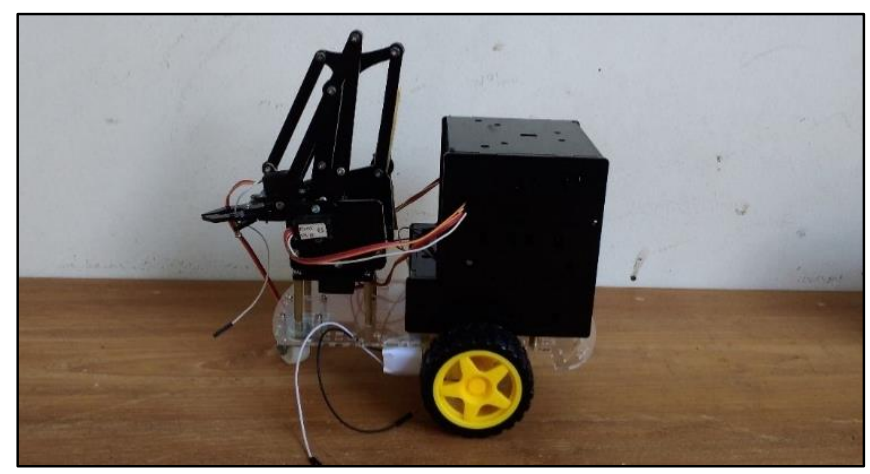

Gambar 2.5 Bentuk Final Komponen Mekanik Robot

\subsection{Perancangan Elektrikal Robot}

Komponen-komponen elektrikal yang dibutuhkan berfungsi sebagai sensor, aktuator, dan mikrokontroller pada robot. Komponen-komponen tersebut disusun menurut rancangan elektrikal pada gambar 2.6 


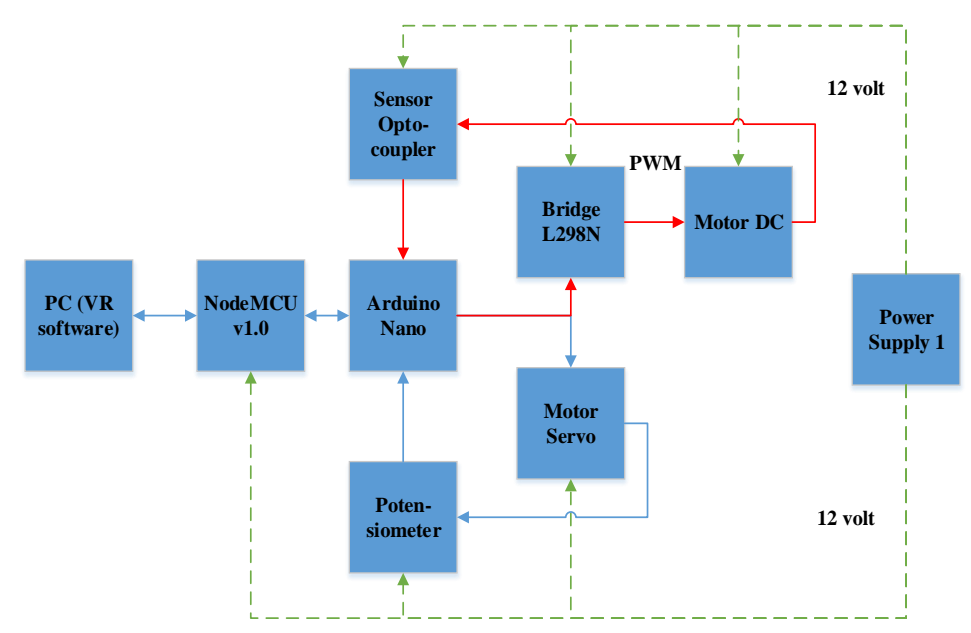

Gambar 2.6 Konfigurasi Komponen Elektronik

\subsection{Perancangan Algoritma Pemrograman Virtual Reality}

Program pada bagian Virtual Reality dirancang pada perangkat lunak Visual Studio menggunakan library default yang ada pada aplikasi Game Engine Unity dan Visual Studio. Program pada bagian sistem robot program dirancang menggunakan library default yang ada pada Arduino dan beberapa library eksternal (import/download) untuk keperluan koneksi jaringan Wi-Fi pada mikrokontroler NodeMCU.

Secara keseluruhan, diagram alir pemrograman sistem robot untuk menggerakkan robot melalui Virtual Environment ditunjukkan pada Gambar 2.7. 


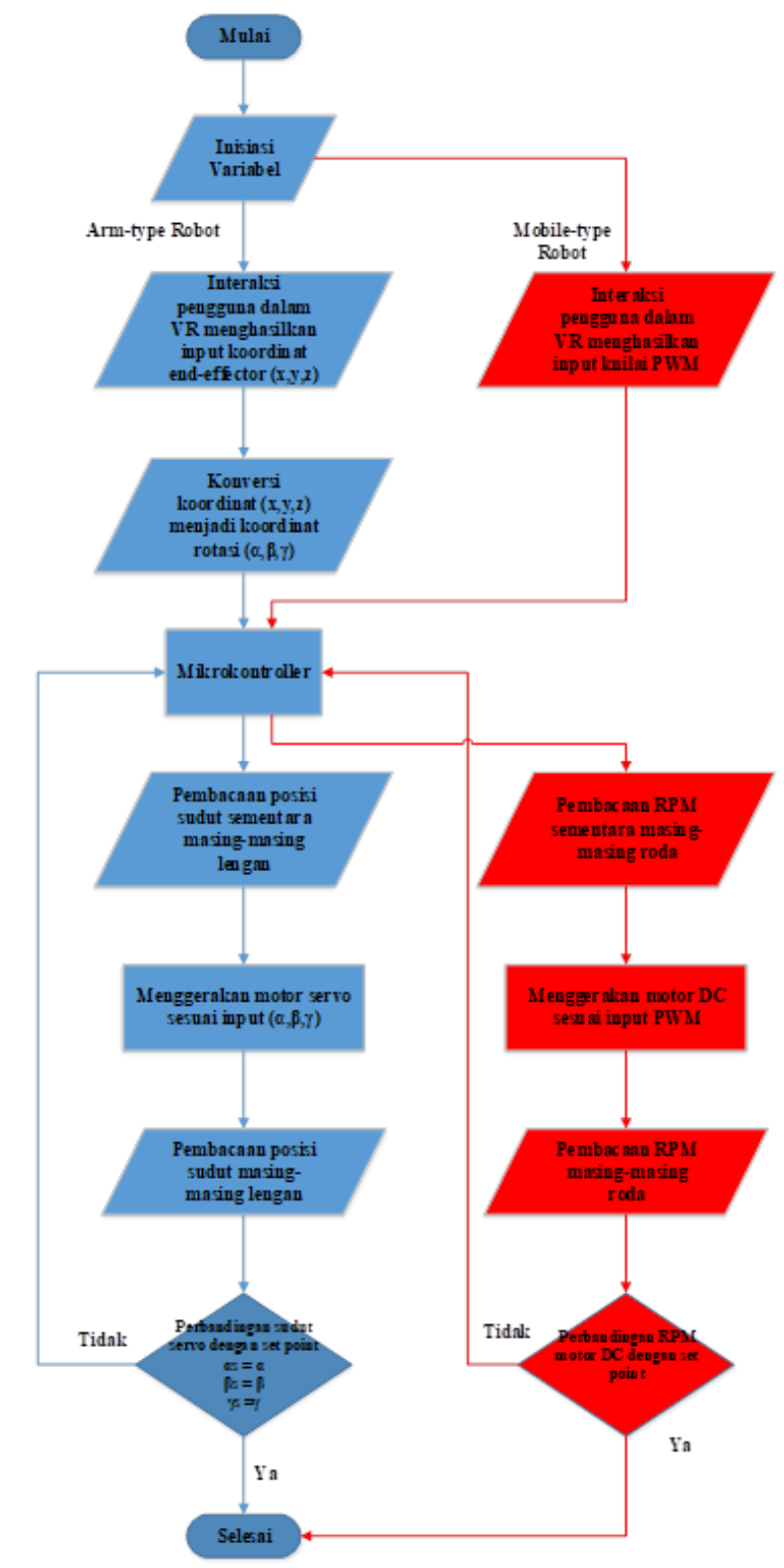

\section{Gambar 2.7 Diagram Alir Pemrograman Penggerak Telerobot melalui Sistem Virtual Reality}

\section{Hasil Sistem Telerobotik}

Terdapat 3 aspek pengujian pertama pengujian beban material melalui analisis simulasi material pada SolidWorks 2017, kedua pengujian sistem komunikasi robot, dan ketiga pengujian akurasi gerakan robot. Berikut hasil dari ketiga pengujian tersebut :

\subsection{Hasil simulasi material pada arm-type robot:}

- $\quad$ Stress maksimum $=6.376 \times 10^{6} \mathrm{~N} / \mathrm{m} 2$

- $\quad$ Stress minimum $=6.109 \times 101 \mathrm{~N} / \mathrm{m} 2$

- Strain maksimum $=1.010 \times 10-3 \mathrm{~mm} / \mathrm{mm}$ 
- Strain minimum $=1.747 \times 10-8 \mathrm{~mm} / \mathrm{mm}$

- Displacement maksimum $=9.633 \times 10-1 \mathrm{~mm}$

- Displacement minimum $=1.000 \times 10-30 \mathrm{~mm}$

Daerah distribusi stress dan strain terbesar: Lengan robot.

Daerah displacement terbesar: end effector.

\subsection{Pengujian Sistem komunikasi arm-type robot:}

Tabel 1 Analisis ANOVA Single Factor Sistem Komunikasi Robot

\begin{tabular}{|c|c|c|c|}
\hline Aspek & Faktor & Rasio F & Fkritis \\
\hline $\begin{array}{c}\text { Pengukuran } \\
\text { Sensor }\end{array}$ & Jarak & 0.607 & 1.962 \\
\cline { 2 - 4 } & Hambatan & 0.065 & 3.949 \\
\hline $\begin{array}{c}\text { Kekuatan } \\
\text { Sinyal WiFi }\end{array}$ & Jarak & 21.539 & $\begin{array}{c}1.021 \times \\
10^{-7}\end{array}$ \\
\cline { 2 - 4 } & Hambatan & 1.704 & 2.725 \\
\hline
\end{tabular}

- Perlakuan jarak dan hambatan yang diberikan tidak mempengaruhi akuisisi data pengukuran.

- Jarak mempengaruhi kekuatan sinyal WiFi, namun hambatan yang diberikan tidak mempengaruhi kekuatan sinyal WiFi.

- Komunikasi data cukup memadai untuk perlakuan yang diberikan.

\subsection{Hasil pengujian akurasi aktuator robot:}

- $\quad$ Motor servo nomor 1 , gerak geleng $(\mathrm{y})=80.45 \%$

- Motor servo nomor 2, gerak angguk $(\alpha)=99.29 \%$

- $\quad$ Motor servo nomor 3, gerak angguk $(\beta)=89.05 \%$

- $\quad$ Motor DC $1=78.37 \%$

- Motor DC $2=81.67 \%$

\section{Diskusi dan Kesimpulan}

Melalui penelitian ini, pendekatan perancangan sistem telerobotik melalui konsep Cyber Physical System dapat dibuktikan berhasil. Konsep Cyber Physical System digunakan untuk merancang keseluruhan arsitektur sistem telerobotik, kemudian dibagi menjadi 3 bagian besar sistem yaitu bagian mekanik, elektrik dan HMI dan backbone jaringan dengan Virtual Reality.

Melalui hasil pengujian simulasi material dapat disimpulkan daerah distribusi stress dan strain terbesar terletak pada lengan robot dan daerah displacement terbesar pada end effector. Hal ini wajar karena penanggungan beban terbesar robot dilakukan oleh bagian lengan dan bagian end effector terkena imbas dalam membawa beban pada capit.

Hasil pengujian sistem komunikasi menunjukan bahwa perlakuan jarak dan hambatan yang diberikan tidak mempengaruhi akuisisi data pengukuran. Selama proses pengiriman sinyal komunikasi masih dapat dilakukan dengan baik oleh sistem maka akuisisi data tidak terlalu terpengaruh. Bagian berikutnya faktor jarak mempengaruhi kekuatan sinyal WiFi, namun hambatan yang diberikan tidak mempengaruhi kekuatan 
sinyal WiFi. Hal ini perlu dipertimbangkan apabila ke depannya dilakukan pengembangan lebih jauh terhadap variasi jarak sistem komunikasi.

Pada hasil pengujian aktuator sistem robot, pembuatan interface dengn Virtual Reality ini menunjukan akurasi yang cukup baik dengan rata-rata hampir di atas $80 \%$ kecuali untuk motor DC 1 . Untuk pengembangan ke depannya seperti peningkatan parameter kontrol pada aktuator akan diprediksi lebih mudah dengan tingkat akurasi yang sudah demikian baik.

Penelitian ini berhasil membuat sistem telerobotik yang dibuat dengan menggunakan interface dan sistem komunikasi Virtual Reality. Dampak yang ditimbulkan melalui penelitian ini adalah memampukannya suatu sistem yang terdiri dari infrastruktur secara virtual yang mampu berinteraksi dengan manusia secara langsung. Banyak potensi teknologi lain dapat dikembangkan dengan mempertimbangkan aspek teknologi baru ini.

\section{Ucapan Terima Kasih}

Special thanks to Daniel Piedrahita from Carnegie Melon University Mechanical Engineering Department for of his inspiring work that initiate this final project and helpful suggestions.

\section{Daftar Pustaka}

[1] K. Ogata, Modern Control Engineering, New Jersey: Prentice Hall, 2002.

[2] I. B. K. Manuaba, "Response Model for Series of Commands in Gaming Environment," in 20162 nd International Conference on Science in Information Technology (ICSITech), Jakarta, Indonesia, 2016.

[3] P. Zhang, Advanced Industrial Control Technology, Burlington: Elsevier, 2010.

[4] F. Soltani, F. Eskandari and S. Golestan, "Developing A Gesture-Based Game For Deaf/Mute People Using Microsoft Kinect," in 2012 Sixth International Conference On Complex, Intelligent, and Software Intensive System, Arak, Iran, 2012.

[5] I.-J. Ding, C.-W. Chang and C.-J. He, "A Kinect Based-Gesture Command Control Method For Human Action Imitations of HUmanoid Robots," in 2014 International Conference on Fuzzy Theory and Its Application, Taiwan, 2014.

[6] F. Mukhlish, E. Ekawati, M. Fakhruroji and I. Amri, "Compensating Wind Disturbance on Gesture Commanded Quadrotor Flight," in International Conference on Advanced Mechatronic, Intelligent Manufacture, and Industrial Automation 2105 (ICAMIMIA), Bandung, Indonesia, 2015.

[7] K. Ashton, Making Sense of IoT: How The Internet of Things Became Humanities Nervous System, California: Hewlett Packard Entreprise, 2017.

[8] L. Monostori, "Cyber-Physical Production System: Roots, Expecetation, and R\&D Challenges," Procedia Cirp, vol. 17, pp. 9-13, 2014.

[9] N. Jazdi, "Cyber Physical Systems in The Context of Industry 4.0," in In Automation, Quality and Testing Robotics, 2014 IEEE International Conference, 2014.

[10] "Thingiverse: MeArm V0.4 - Pocket Sized Robot Arm," Thingiverse, 1442014. [Online]. Available: https://www.thingiverse.com/thing:298820. [Accessed 134 2017]. 
Seminar Nasional Instrumentasi, Kontrol dan Otomasi (SNIKO) 2018

Bandung, Indonesia, 10-11 Desember 2018 